\title{
Trace Analysis of a Beryllium Window for a Solid State Detector System by Inductively Coupled Plasma Mass Spectrometry
}

\author{
Shuji Kozono*, Taizo ItoH*, Atsushi Yoshinaga**, Shinji OHKawa*** and Kenji YakushiJi*** \\ *Showa Denko K. K. Central Research Laboratory, Ohnodai, Midori-ku, Chiba 267, Japan \\ **Showa Denko K. K. Chichibu Works, Shimokagemori, Chichibu, Saitama 369-18, Japan \\ ***Showa Denko Silicon K. K., Shimokagemori, Chichibu, Saitama 369-18, Japan
}

\begin{abstract}
Transition metallic impurities in high-purity Be for a window of the solid state detector (SSD) of a commercially available total-reflection X-ray fluorescence (TXRF) analyzer were determined by the use of ICP-MS analysis. From this analysis, $150 \mu \mathrm{g} / \mathrm{g}$ of $\mathrm{Fe}$ and $100 \mu \mathrm{g} / \mathrm{g}$ of $\mathrm{Ni}$ were detected. Other impurities were less than $55 \mu \mathrm{g} / \mathrm{g}$. In the determination of trace metallic impurities (of the order of $10^{10}$ atoms $/ \mathrm{cm}^{2}$ ) on Si wafer surfaces by TXRF, X-ray fluorescence, such as $\mathrm{Fe} \mathrm{K}_{\alpha}$ and $\mathrm{Ni} \mathrm{K}_{\alpha}$, are known to be observed, even if these elements do not actually exist on the surface. These spurious peaks appear when the primary beam of $\mathrm{W}_{\beta}$ radiation satisfies the Bragg condition and the diffracted beam is detected by SSD. From our investigation, impurities in Be were found to be one of the origins of this phenomenon, because the diffracted $\mathrm{W} \mathrm{L}_{\beta}$ radiation which is impinged into the SSD through the Be window excites the impurity in the window.
\end{abstract}

Keywords Beryllium, solid state detector, metallic impurity, trace analysis, inductively coupled plasma mass spectrometry, total-reflection X-ray fluorescence, silicon wafer

By employing a rotating anode X-ray generator of $\mathrm{W} \mathrm{L}_{\beta}$ radiation, the technique of total-reflection $\mathrm{X}$-ray fluorescence (TXRF) has recently achieved great improvement in the detection limit, which is now of the order of $10^{10}$ atoms $/ \mathrm{cm}^{2} .^{1}$ In this detection limit, it was found that $\mathrm{Fe} \mathrm{K}_{\alpha}$ and $\mathrm{Ni} \mathrm{K}_{\alpha}$ radiation is observed as impurities. However, their intensities depend on the intensity of $\mathrm{W} \mathrm{L}_{\beta}$ radiation, which is detected by a solid state detector (SSD). It also varies with the incident conditions of the primary X-ray beam. ${ }^{2-4}$ Such a variation of the $W L_{\beta}$ radiation with the incident beam direction is now known to depend on how the incident beam satisfies the Bragg condition. ${ }^{4}$ These facts cause us some uncertainty in the determination of trace impurities on sample wafers. Our systematic investigations $^{5,6}$ to determine the origin of this phenomenon led us to the conclusion that these $\mathrm{Fe}$ and $\mathrm{Ni} \mathrm{K}_{\alpha}$ peaks are spurious and have no relation to the trace impurities of sample wafers. ${ }^{7}$ The primary radiation and the SSD system are considered to be origins of these impurity peaks. High-purity $\mathrm{Be}$ is usually used as a window material of SSD in order to prevent any contamination on a $\mathrm{Si}(\mathrm{Li})$ crystal, since $\mathrm{Be}$ is relatively transparent to $\mathrm{X}$ rays. However, there is no assurance concerning the impurities of Be material, although it is known to contain $\mathrm{Fe}$ and $\mathrm{Ni}$ as the main impurities ${ }^{8}$, since no trace determination of the high-purity Be has so far been reported for this decade. Since inductively coupled plasma mass spectrometry (ICP-MS) is widely used as one of the most sensitive analyzers for the quantitative analysis of trace elements in liquids, we determined the trace impurities in a $\mathrm{Be}$ window for SSD by ICP-MS. In this paper, we present the results of this analysis.

\section{Experimental}

Three Be windows for SSD of $16 \mathrm{~mm}$ diameter and $25 \mu \mathrm{m}$ thickness were analyzed. The samples were supplied from Technos Inc., which is one of the major makers of TXRF analyzers.

We cleaned a $3.0-3.5 \mathrm{mg}$ of the Be sample by shaking in $8 \mathrm{M} \mathrm{HNO}$ (Tama Chemical Co., Japan) at room temperature. This sample was dissolved with $5 \mathrm{ml}$ of $10 \mathrm{M} \mathrm{HCl}$ (Tama Chemical Co.) in a PFA (perfluoroalkoxy resin) vessel at $80^{\circ} \mathrm{C}$. No residue remained after this process. The final volume was adjusted to $10 \mathrm{ml}$.

As the blank solution, $50 \mathrm{ml}$ of $10 \mathrm{M} \mathrm{HCl}$ was diluted to $100 \mathrm{ml}$. A standard solution containing $10 \mathrm{ppb}$ of each element ( $\mathrm{Fe}, \mathrm{Ni}$ and so on) was prepared by mixing standard solutions for AAS (1000 ppm, Kanto Chemical Co., Inc., Japan) and a $10 \mathrm{M} \mathrm{HCl}$ solution.

Sample preparations were carried out inside a clean draft of class-100 in a class-1000 clean room. Potassium, Ca, Sc, Ti, V, Cr, Mn, Fe, Co, Ni, $\mathrm{Cu}$ and $\mathrm{Zn}$ 
Table 1 Operating conditions for ICP-MS

RF power
Sampling depth
Carrier gas flow rate
$\mathbf{H}_{2}$ gas flow rate
Plasma gas flow rate
Auxiliary gas flow rate

$$
\begin{aligned}
& 1.2 \mathrm{~kW} \\
& 15 \mathrm{~mm} \\
& 1.11 / \mathrm{min} \\
& 0.041 / \mathrm{min} \\
& 161 / \mathrm{min} \\
& 1.21 / \mathrm{min}
\end{aligned}
$$

\begin{tabular}{|c|c|c|c|}
\hline & & $\mathbf{K}$ & $\mathrm{Ca}$ \\
\hline $\begin{array}{l}\text { Waveler } \\
\text { Slit wid } \\
\text { Slit heig } \\
\text { Determi } \\
\text { Acquisi }\end{array}$ & $\mathrm{me} / \mathrm{s}$ & $\begin{array}{l}766.5 \\
\quad 1.40 \\
\text { low } \\
\text { integration } \\
\quad 3\end{array}$ & $\begin{array}{l}422.7 \\
\quad 0.70 \\
\text { low } \\
\text { integration } \\
\quad 5\end{array}$ \\
\hline \multicolumn{4}{|c|}{ [Temperature program] } \\
\hline $\mathbf{K}$ & $\begin{array}{r}150^{\circ} \mathrm{C} \\
1000^{\circ} \mathrm{C} \\
2000^{\circ} \mathrm{C}\end{array}$ & $\begin{array}{l}30 \mathrm{~s} \\
30 \mathrm{~s}\end{array}$ & $\begin{array}{r}30 \mathrm{~s} \\
10 \mathrm{~s} \\
3 \mathrm{~s}\end{array}$ \\
\hline $\mathrm{Ca}$ & $\begin{array}{r}150^{\circ} \mathrm{C} \\
800^{\circ} \mathrm{C} \\
2800^{\circ} \mathrm{C}\end{array}$ & $\begin{array}{r}5 \mathrm{~s} \\
10 \mathrm{~s}\end{array}$ & $\begin{array}{r}25 \mathrm{~s} \\
20 \mathrm{~s} \\
5 \mathrm{~s}\end{array}$ \\
\hline
\end{tabular}

Electrothermal vaporizing conditions

\begin{tabular}{lrrrr} 
& \multicolumn{4}{c}{ Heating cycle } \\
& 1 & 2 & 3 & 4 \\
Temperature $/{ }^{\circ} \mathrm{C}$ & 110 & 300 & 600 & 2000 \\
Ramp time $/ \mathrm{s}$ & 30 & 30 & 20 & \\
Hold time $/ \mathrm{s}$ & 20 & 10 & 10 & 5 \\
\hline
\end{tabular}

Table 2 Analytical elements and masses

\begin{tabular}{llcc}
\hline Element & Mass & Element & Mass \\
\hline$(\mathrm{K})$ & (AAS) & $\mathrm{Mn}$ & 55 \\
$(\mathrm{Ca})$ & (AAS) & $\mathrm{Fe}$ & 56 \\
$\mathrm{Sc}$ & 45 & $\mathrm{Co}$ & 59 \\
$\mathrm{Ti}$ & 48 & $\mathrm{Ni}$ & 58 \\
$\mathrm{~V}$ & 51 & $\mathrm{Cu}$ & 65 \\
$\mathrm{Cr}$ & 52 & $\mathrm{Zn}$ & 64 \\
\hline
\end{tabular}

Table 3 Operating conditions for FL-AAS

could be determined, because their $K_{\alpha}$ lines could be excited by the primary beam of $\mathrm{W} \mathrm{L}_{\beta}$ radiation. ICPMS measurements were performed on a graphite-furnace electrothermal vaporizer EV-300 (Seiko Instruments Inc., Tokyo, Japan) connected to an SPQ-8000 quadrupole mass analyzer (Seiko Instruments Inc.). Potassium and $\mathrm{Ca}$ could be determined by flameless atomic absorption spectroscopy (FL-AAS), because these peaks of ICP-MS overlapped with other peaks. ${ }^{39} \mathrm{~K}^{+}$was overlapped by ${ }^{38} \mathrm{Ar}^{1} \mathrm{H}^{+}$and ${ }^{40} \mathrm{Ca}^{+}$was overlapped by ${ }^{40} \mathrm{Ar}^{+}$. The FL-AAS measurement was performed on a Z-5100PC (Perkin-Elmer, Norwalk, CT,

\begin{tabular}{|c|c|c|c|c|}
\hline \multirow{2}{*}{ Element } & \multicolumn{3}{|c|}{$\mathrm{Be}$} & \multirow{2}{*}{ D.L. $(10 \times \sigma)$} \\
\hline & No. 1 & No. 2 & No. 3 & \\
\hline $\mathbf{K}$ & 3.5 & 3.9 & 3.8 & 2 \\
\hline $\mathrm{Ca}$ & 11 & 9.7 & 9.4 & 2 \\
\hline $\mathrm{Sc}$ & $<15$ & $<15$ & $<15$ & 15 \\
\hline $\mathbf{T i}$ & $<15$ & $<15$ & $<15$ & 15 \\
\hline V & $<15$ & $<15$ & $<15$ & 15 \\
\hline $\mathrm{Cr}$ & 54 & 48 & 48 & 5 \\
\hline Mn & 12 & 9.4 & 8.7 & 0.5 \\
\hline $\mathrm{Fe}$ & 180 & 150 & 160 & 2 \\
\hline Co & 0.8 & 0.7 & 0.7 & 0.5 \\
\hline $\mathrm{Ni}$ & 110 & 110 & 100 & 5 \\
\hline $\mathrm{Cu}$ & 19 & 19 & 18 & 0.5 \\
\hline $\mathrm{Zn}$ & 9.0 & 8.0 & 8.7 & 0.5 \\
\hline
\end{tabular}
USA). The operating conditions of ICP-MS are listed in Table 1. The elements determined and their masses are listed in Table 2. The operating conditions of the FL-AAS analysis are also given in Table 3.
Table 4 Results of the determination and detection limits

In order to prevent any influence of the matrix, the analysis was performed using the conventional standard addition method.

\section{Results and Discussion}

The results of the ICP-MS measurement and the detection limits of each element are listed in Table 4. The detection limit was defined as 10-times the standard deviation, which was calculated from 5 measurements of the blank solution. From this analysis, it is found that the Be window contained approximately $150 \mu \mathrm{g} / \mathrm{g}$ of $\mathrm{Fe}$, $100 \mu \mathrm{g} / \mathrm{g}$ of $\mathrm{Ni}, 20 \mu \mathrm{g} / \mathrm{g}$ of $\mathrm{Cu}$ and $10 \mu \mathrm{g} / \mathrm{g}$ of $\mathrm{Zn}$.

The intensities of the fluorescent X-rays of the impurities originating from the $\mathrm{Be}$ window were estimated in the following way. ${ }^{9}$ The emission probability of the fluorescent X-ray of element $i$ is given by,

$$
Q_{\mathrm{i}}\left(\lambda_{0}\right)=\frac{\mu_{\mathrm{i}}\left(\lambda_{0}\right)}{\rho_{\mathrm{i}}} W_{\mathrm{i}} K_{\mathrm{i}} \omega_{\mathrm{i}} R_{\mathrm{K}}^{\mathrm{i}}
$$

where $\lambda_{0}$ is the wavelength of the primary beam, $\mu_{\mathrm{i}}\left(\lambda_{0}\right)$ the linear absorption coefficient for X-rays of wavelength $\lambda_{0}$, $\rho_{\mathrm{i}}$ the density, $W_{\mathrm{i}}$ the weight fraction, $K_{\mathrm{i}}$ the absorption jump, $\omega_{\mathrm{i}}$ the fluorescent yield and $R$ the intensity fraction of the K-line in the characteristic X-ray series to which $\mathrm{K}$ line belongs, respectively. Suffix i means element. In general, in the case of a transparent configuration, the intensity of fluorescent $\mathrm{X}$-rays per unit area is given by

$$
\begin{aligned}
I_{1}= & \int_{0}^{d} \rho Q_{i}\left(\lambda_{0}\right) I_{0}\left(\lambda_{0}\right) \exp \frac{-\mu\left(\lambda_{0}\right) x}{\sin \Phi} \\
& \exp \frac{-\mu\left(\lambda_{\mathrm{ip}}\right)(d-x)}{\sin \Psi} \mathrm{d} x,
\end{aligned}
$$

where $\rho$ is the density of the sample, $Q_{\mathrm{i}}$ is given by Eq. (1), $I_{0}$ is the intensity of the primary beam, $d$ is the thickness of the sample, $\Phi$ is the incident angle of the primary beam, $\Psi$ is the take-off angle of the fluorescent X-ray, $\lambda_{\text {ip }}$ is the wavelength of the fluorescent $X$-ray, respectively. 
Table 5 Estimated intensity of the spurious peaks from impurities in a Be window

\begin{tabular}{cc}
\hline Element & Estimated intensity of fluorescent X-ray, cps \\
\hline $\mathrm{K}$ & $<10^{-4}$ \\
$\mathrm{Ca}$ & $<10^{-4}$ \\
$\mathrm{Sc}$ & $<10^{-4}$ \\
$\mathrm{Ti}$ & $<10^{-4}$ \\
$\mathrm{~V}$ & $<10^{-4}$ \\
$\mathrm{Cr}$ & $2.0-2.3 \times 10^{-3}$ \\
$\mathrm{Mn}$ & $3.4-5.1 \times 10^{-4}$ \\
$\mathrm{Fe}$ & $0.8-1.0 \times 10^{-2}$ \\
$\mathrm{Co}$ & $<10^{-4}$ \\
$\mathrm{Ni}$ & $7.8-8.6 \times 10^{-3}$ \\
$\mathrm{Cu}$ & $1.6-1.7 \times 10^{-3}$ \\
$\mathrm{Zn}$ & $8.2-9.2 \times 10^{-4}$ \\
\hline
\end{tabular}

In our experiment, $\Phi$ and $\Psi$ were $90^{\circ}$. The concentrations of the impurity elements which were determined by ICP-MS were so low that the absorption of the primary fluorescent X-ray by these impurities could be neglected. Then, the total intensity of the fluorescent X-ray was obtained by multiplying the area of sample, (S), by Eq. (2),

$$
I_{\mathrm{i}}^{\text {total }}=S \rho Q_{\mathrm{i}}\left(\lambda_{0}\right) I_{0}\left(\lambda_{0}\right) \int_{0}^{d} \exp \left(-\mu\left(\lambda_{0}\right) x\right) \exp \left(-\mu\left(\lambda_{\mathrm{ip}}\right)(d-x)\right) \mathrm{d} x .
$$

Using Eq. (3), the intensities of the X-ray fluorescence emitted by the impurities in the $\mathrm{Be}$ window were calculated. Since the emitted X-rays are spread in an omni-direction, we estimated that $40 \%$ of the fluorescent $\mathrm{X}$-rays are detected by SSD.

The results of the calculation are listed in Table 5. In this calculation, the detected intensity of $W L_{\beta}$ radiation was assumed to be $300 \mathrm{cps}$ ( $I_{0}$ of Eq. (1) was set to $301.3 \mathrm{cps}$ ). The estimated intensities of fluorescent $\mathrm{X}$ rays from $\mathrm{Fe}$ and $\mathrm{Ni}$ in the $\mathrm{Be}$ window are $0.8-1.0 \times 10^{-2}$ and $7.8-8.6 \times 10^{-3} \mathrm{cps}$, and those from other impurities, such as $\mathrm{Cr}, \mathrm{Mn}, \mathrm{Cu}$ and $\mathrm{Zn}$, are lower than $2.5 \times 10^{-3} \mathrm{cps}$. In Fig. 1, the integrated intensities of $\mathrm{Fe} \mathrm{K}_{\alpha}$ and $\mathrm{Ni} \mathrm{K}_{\alpha}$ radiation are plotted against the detected intensity of the $W L_{\beta}$ radiation. $^{3}$ The error bars were calculated from the square root of the X-ray counts, including the background. From this figure, it is found that intensities of the $\mathrm{Fe} \mathrm{K} \mathrm{K}_{\alpha}$ and $\mathrm{Ni} \mathrm{K} \mathrm{K}_{\alpha}$ radiation are approximately $0.07 \mathrm{cps}$ and $0.14 \mathrm{cps}$, respectively, when the detected intensity of $\mathrm{W} \mathrm{L}_{\beta}$ radiation is $300 \mathrm{cps}$. From these results, it is estimated that 12 to $15 \%$ of the $\mathrm{Fe}$ spurious peak and 5 to $6 \%$ of the $\mathrm{Ni}$ spurious peak originated from impurities in the Be window. In Fig. 2, a typical TXRF spectrum of impurity peaks observed from a Si (001) wafer is shown. ${ }^{3}$ The abscissa indicates the energy of the X-rays and the ordinate the intensity of the peak in units of counts per second (cps). The Fe $\mathbf{K}_{\alpha}$ and $\mathrm{Ni} \mathrm{K}_{\alpha}$ peaks indicated in this figure are spurious peaks. On the other hand, no X-ray fluorescent peaks from other impurities, such as $\mathrm{Cr}, \mathrm{Mn}, \mathrm{Cu}$ and $\mathrm{Zn}$, was found. However, as is shown in Table 4, these impurities

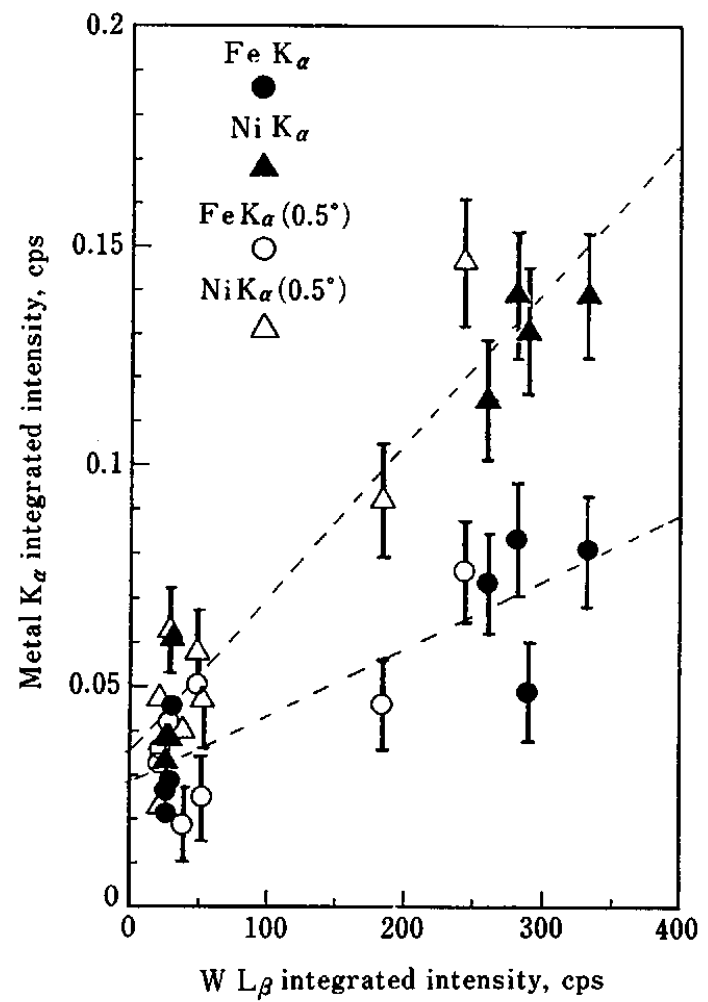

Fig. 1 Integrated intensities of $\mathrm{Fe} \mathrm{K}_{\alpha}$ and $\mathrm{Ni} \mathrm{K}_{\alpha}$ radiation against the intensity of the $W L_{\beta}$ radiation detected by the SSD for the exact (001) wafer and the vicinal (001) wafer with a misorientation angle of $0.5^{\circ}$. These data were measured using the results given in Fig. 2. The error bars were calculated from the square root of the X-ray counts including background.

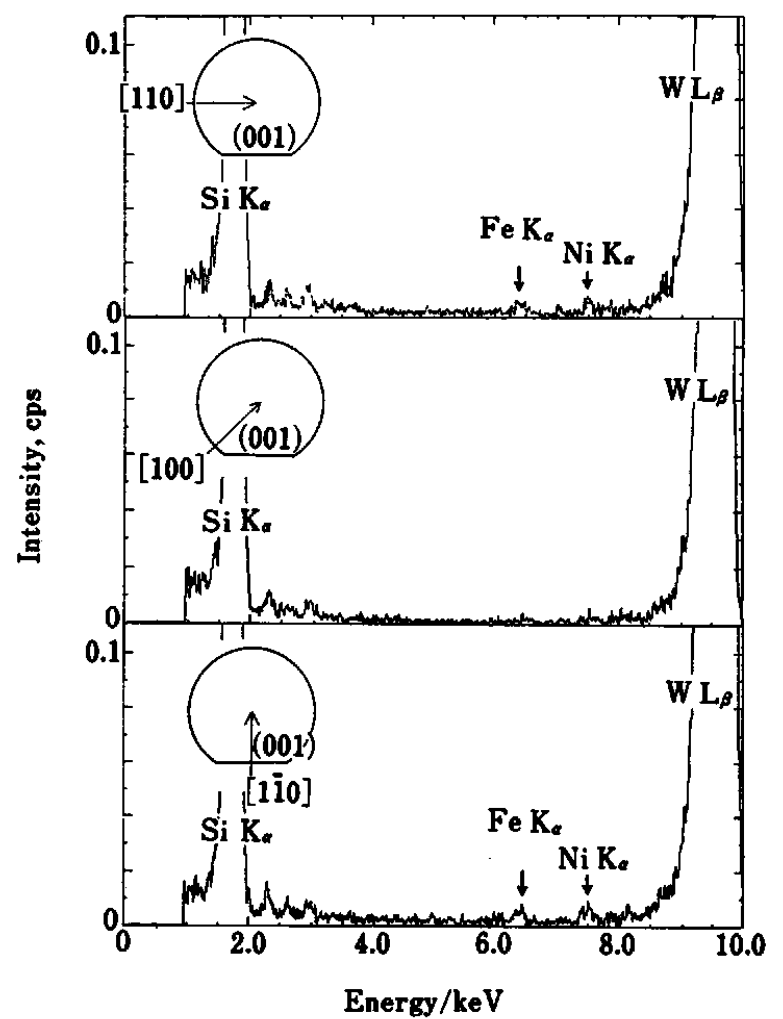

Fig. 2 Typical impurity spectra of TXRF. Fe $\mathrm{K}_{\alpha}$ and Ni $\mathrm{K}_{\alpha}$ peaks are spurious peaks. 
were found to be contained in a $\mathrm{Be}$ window at concentration levels of around $10-50 \mu \mathrm{g} / \mathrm{g}$. This means that even if an element is contained in the $\mathrm{Be}$ window as an impurity, it will not contribute to the spurious peak in the case that its estimated intensity of fluorescent X-ray is lower than $2.5 \times 10^{-3} \mathrm{cps}$ in Table 5 . From this fact, it is concluded that in order to suppress the spurious peak intensities originating from $\mathrm{Fe}$ and $\mathrm{Ni}$ in a Be window, these concentrations should be reduced to lower than $40 \mu \mathrm{g} / \mathrm{g}$ and $25 \mu \mathrm{g} / \mathrm{g}$, respectively. Our study shows for the first time that the impurities on the light path of the diffracted primary beam should be considered to be the origin of the spurious peaks. In the same way, the impurities in every part of the components of SSD, such as the surface of the Be window, the surface of $\mathrm{Si}(\mathrm{Li})$ crystal, the casing of the SSD and so on, should be studied in order to determine any other origins of spurious peaks.

The authors would like to thank Professor Jimpei Harada of Nagoya University for general discussions concerning the TXRF analysis and spurious peaks.

\section{References}

1. K. Nishihagi, A. Kawabata, T. Taniguchi and S. Ikeda, “Semiconductor Cleaning Technology/1989", ed. J. Ruzyllo and R. E. Novak, Vol. 90-9, p. 243, Electrochemical Society, Pennington, 1990.

2. K. Yakushiji and S. Ohkawa, Advances in X-ray Chemical Analysis Japan, 24, 97 (1993) [in Japanese].

3. K. Yakushiji, S. Ohkawa, A. Yoshinaga and J. Harada, Jpn. J. Appl. Phys., 32, 1191 (1993).

4. K. Yakushiji, S. Ohkawa, A. Yoshinaga and J. Harada, Jpn. J. Appl. Phys., 31, 2872 (1992).

5. K. Yakushiji, S. Ohkawa, A. Yoshinaga and J. Harada, Jpn. J. Appl. Phys., 33, 1130 (1994).

6. K. Yakushiji, S. Ohkawa, A. Yoshinaga and J. Harada, submitted to Advances in X-ray Chemical Analysis Japan, 25, 213 (1994) [in Japanese].

7. K. Yakushiji, S. Ohkawa, A. Yoshinaga and J. Harada, Jpn. J. Appl. Phys., 32, 4750 (1993).

8. "Shinkinzoku Data Book (New Metal Data Book, in Japanese)", ed. Kinzoku Jihyo editorial office, p. 588, Homat Ad, Tokyo, 1985.

9. T. Shiraiwa and N. Fujino, Jpn. J. Appl. Phys., 5, 886 (1966).

(Received October 6, 1993)

(Accepted February 15, 1994) 